\title{
A Simple Mathematical Model for a New Type of Cancer Cells
}

\author{
E Ahmed* \\ Department of Mathematics, Faculty of Science, Egypt
}

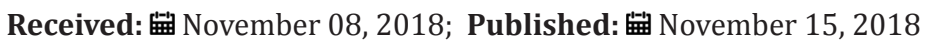

*Corresponding author: E Ahmed, Department of Mathematics, Faculty of Science, Egypt

\begin{abstract}
Recently new type of cancer cells has been observed. It is called Hybrid cells. A simple mathematical model is proposed to describe them. It implies that they will be near the tumor surface or circulating. Some comments about the possibility of their reaching brain are given.
\end{abstract}

\section{Introduction}

\section{Hybrid tumor Cells}

Recently $[1,2,3,4]$ hybrid tumor cells have been discovered. They have the following properties:

a) They circulate more than ordinary tumor cells.

b) They have greater ability to migrate and invade other tumors.

c) They have greater ability to form metastases.

Motivated by this the following simple model is presented:

Let N1, N2 be the ordinary and hybrid tumor cells respectively. Let $\mathrm{N}=\mathrm{N} 1+\mathrm{N} 2$ hence the tumor growth can be represented by

$d N 1 / d t=r 1 N 1^{\wedge}(2 / 3)-N, d N 2 / d t=r 2 N 2^{\wedge}(2 / 3)-N$,

The equilibrium solution for the coexistence of both types is:

$$
\begin{array}{r}
N 1 e q=[r 1 /(1+(r 1 / r 2) \wedge 3 / 2)] \wedge 3 \\
N 2 e q=([r 1 / r 2] \wedge 3 / 2)[r 1 /(1+(r 1 / r 2) \wedge 3 / 2)] \wedge 3
\end{array}
$$

It is unstable.

The single species solution is

$$
N 1=r 1^{\wedge} 3, N 2=0,
$$

\section{And it is stable if $\mathrm{r} 1>2 / 3$.}

Hence the following conclusion is reached: If $r 2>r 1>2 / 3$ then most tumors consist of ordinary (non-hybrid) cells. Hybrid cells exist near tumor surface OR circulate.

\section{Conclusion}

Since hybrid cells have a greater ability to invade other cells, it is expected that they will invade brain cells. Hence brain diseases can be a good source for identifying them. Moreover, trying to attract them to less important sites can be a feasible strategy to deal with them. It will be difficult to test this idea experimentally, because the hybrid state will not be stable.

\section{References}

1. Gast (2018) Cell fusion potentiates tumor heterogeneity and reveals circulating hybrid cells that correlate with stage and survival. Sci Adv 4(9): eaat7828.

2. Ievgenia Pastushenko (2018) Identification of the tumour transition states occurring during EMT. Nature 556(7702): 463-468.

3. MK Jolly, S Mani, H Levine (2018) Hybrid epithelial/mesenchymal phenotype(s): The 'fittest' for metastasis? BBA Reviews on cancer 1870(2): 151-157.

4. K Campbell (2018) Contribution of epithelial-mesenchymal transitions toorganogenesis and cancer metastasis. Current Opinion Cell Biol 55: 30-35. 
(c) This work is licensed under Creative

To Submit Your Article Click Here: $\quad$ Submit Article

DOI: $10.32474 /$ СTBB.2018.01.000106

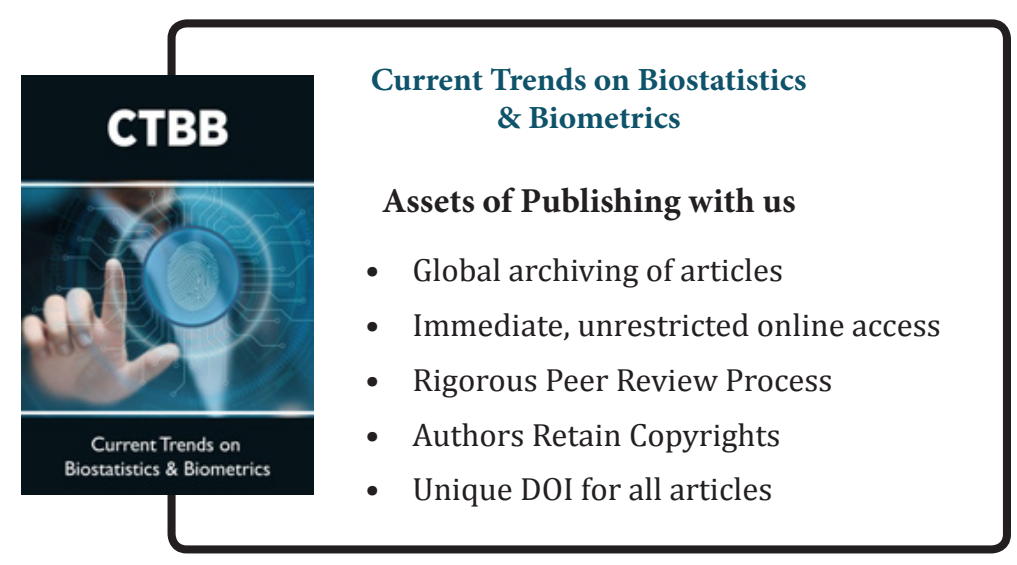

